\title{
DERMOSCOPIC EVALUATION OF THERAPEUTIC RESPONSE IN ALOPECIA AREATA
}

\author{
Arun Achar1, Loknath Ghoshal2, Smriti Chowdhury3 \\ ${ }_{1}^{1}$ Associate Professor, Department of Dermatology, NRS Medical College and Hospital, Kolkata, West Bengal, India. \\ ${ }^{2}$ Associate Professor, Department of Dermatology, Medical College Hospital, Kolkata, West Bengal, India. \\ ${ }^{3}$ Resident, Department of Dermatology, NRS Medical College and Hospital, Kolkata, West Bengal, India.
}

\begin{abstract}
\section{BACKGROUND}

Alopecia areata (AA) is an idiopathic, non-scarring form of alopecia with wide range of clinical presentations from patchy alopecia to complete loss of scalp hair (Alopecia totalis) and or the entire body (Alopecia universalis). It affects $1.7 \%$ of the population at some point in their lives and is a source of much anxiety. Dermatoscopic findings used to assess and compare the progress are yellow dots, black dots, broken hairs, exclamation mark hair and coudability hair which decrease in number following therapy. On the other hand, the presence of short vellus hair and circle hair within the patch is indicative of remitting disease. The present study was conducted to evaluate and describe the role of dermatoscopy in prediction of the response to therapy monitoring response thereof. There was no similar study to the best of our knowledge at the time of authoring the manuscript.
\end{abstract}

\section{METHODS}

This was a prospective observational study conducted with 24 patients with alopecia areata to characterize the clinical and dermatoscopy findings of alopecia areata and describe the progress of dermatoscopy changes, with treatment. In all cases, following clinical diagnosis, informed consent was taken. Detailed recording of demographic data, comprehensive history taking, and thorough clinical examination was done. The dermoscopic parameters of the patch were recorded.

\section{RESULTS}

Yellow dots are a sensitive indicator of remission of the condition, reduction being significant at as early as 4 weeks and also significant at 8 weeks. Thus, it was both a sensitive and specific indicator of response to treatment. The reduction of number of patients with vellus hairs at 8 weeks was significant and so was the decrease of broken hairs.

\section{CONCLUSIONS}

Exclamation hair is said to be specific to diagnosis of AA. However, the decrease of number of patients with EH was significant neither at 4 weeks nor at 8 weeks in the present study.

\section{KEY WORDS}

Alopecia Areata, Dermoscopy, Response to Treatment

HOW TO CITE THIS ARTICLE: Achar A, Ghoshal L, Chowdhury S. Dermoscopic evaluation of therapeutic response in alopecia areata J. Evolution Med. Dent. Sci. 2019;8(25):1974-1978, DOI: 10.14260/jemds/2019/434

\section{BACKGROUND}

Alopecia areata (AA) is an autoimmune, non-scarring form of alopecia with wide range of clinical presentations from patchy alopecia to complete loss of scalp hair (Alopecia totalis) and or the entire body (alopecia universalis). ${ }^{1}$ The disease affects most commonly scalp hairs, but it may also involve eyebrows, eyelashes, beard, pubic, axillary hair and others. The exact pathogenesis of the disease yet remains to be clarified; however autoimmune, genetic and environmental factors have been implicated. Alopecia areata occurs in populations worldwide. It affects $1.7 \%$ of the population at some point in their lives ${ }^{1}$. Sixty percent of patients present with their first patch before 20 years of age and thus patients present with considerable anxiety. ${ }^{2}$

Treatment modalities are varied and depend on different factors like progression of disease, size, site and duration of

'Financial or Other Competing Interest': None.

Submission 24-05-2019, Peer Review 13-06-2019,

Acceptance 15-06-2019, Published 24-06-2019.

Corresponding Author:

Dr. Loknath Ghoshal,

Department of Dermatology,

Medical College, 88 College Street,

Kolkata-700073, West Bengal, India.

E-mail: loknathghoshal@gmail.com

DOI: $10.14260 /$ jemds $/ 2019 / 434$ the diseases. Spontaneous regression can occur in up to $80 \%$ cases with limited patchy hair loss for short duration. ${ }^{3}$ Intra-lesional injection of corticosteroids has an important role for treatment. ${ }^{4}$ Hydrocortisone acetate and triamcinolone injection are used either by needle injection or jet injection. Long term daily steroids can also be used with tapering doses. ${ }^{5}$ There are several publications reporting high dose pulse steroid treatment for alopecia areata. ${ }^{6-9}$

Contact immunotherapy with some contact allergen was first introduced by Rosenberg in 1979. Different contact allergens like dinitrochlorobenzene (DNCB), squaric acid dibutyl ester (SADBE) and diphenylcyclopropenone (DPCP) can be used. Some published articles on contact immunotherapy concluded that about $50-60 \%$ of patients have useful results, but response rate varies widely from 9-87 $\%$. Patients with extensive hair loss are less likely to improve. ${ }^{10-12}$

There are several uncontrolled studies of PUVA for alopecia areata using all type of PUVA (oral or topical psoralen, local or whole-body UVA irradiation.13,14,15,16

Minoxidil can be used in different type of alopecia areata with unpredictable results. ${ }^{17,18,19}$

Dithranol can be used in different type of alopecia areata as contact irritant. ${ }^{20}$ Dermatoscopy or incident light microscopy is a non-invasive technique that allows a rapid and magnified in vivo observation of skin, hair or nail with 
visualisation of morphological features invisible to the naked eye. ${ }^{21}$

Dermatoscopic findings used to assess and compare the progress are yellow dots, black dots, broken hairs, exclamation mark hair and coudability hair which decrease in number following therapy. On the other hand, the presence of short vellus hair and circle hair within the patch is indicative of remitting disease. ${ }^{21}$ The present study was conducted to evaluate and describe the role of dermatoscopy in prediction of the response to therapy monitoring response thereof. There was no similar study to the best of our knowledge at the time of authoring the manuscript.

\section{Aims and Objectives}

1. Characterize the clinical and dermatoscopy findings of alopecia areata.

2. Describe the extent of changes in dermatoscopy findings with treatment.

\section{METHODS}

This was a prospective observational study conducted with 24 patients with alopecia areata who attended the dermatology outpatients department (OPD) of tertiary care hospital in Kolkata from November 2017 to April 2018.

\section{Calculation of Sample Size}

We conducted an informal pilot phase of a week in which we estimated the number of newly attending alopecia areata patients at the OPD. The average total number of patients was 398 per day, newly attending patients with alopecia areata was $3.5 \%$. Keeping confidence level at $80 \%$ and confidence limit of $5 \%$ we calculated the sample size to be 22 .

\section{Case Definition}

Patients with acquired loss of hair from any circumscribed area without clinical inflammation or scarring were labelled as suitable cases.

The inclusion criteria included newly diagnosed (untreated) patients with alopecia areata in any site and willing to participate in the study. Exclusion criteria included patients with infection or secondary changes.

In all cases following clinical diagnosis, informed consent was taken. Detailed recording of demographic data like age, sex, residence, occupation followed by comprehensive history taking and thorough clinical examination was done. The dermoscopic parameters of the patch were recorded which included black dots, yellow dots, vellus hair, broken hair, coudability hair and circle hair. A digital dermatoscope Dinolite $\AA$ (of magnification $\times 25-60$ ) was used for this purpose. The parameters for each patch were recorded in first visit as baseline findings and then compared with the findings in subsequent visits during treatment (1 ${ }^{\text {st }}$ month and $2^{\text {nd }}$ month).

The changes in all dermatoscopy parameters were recorded by estimating their increase or decrease as compared to their own baseline pictures in 2 consecutive monthly follow up visits.

\begin{tabular}{|c|c|c|c|}
\hline Parameter & Sociodemographic Factors & Number & \% \\
\hline Age group & $0-14$ & 6 & 25 \\
\hline & $15-29$ & 6 & 25 \\
\hline & $30-45$ & 12 & 50 \\
\hline
\end{tabular}

\begin{tabular}{|c|c|c|c|}
\hline Gender & Male & 8 & 33 \\
\hline & Female & 16 & 67 \\
\hline Residence & Rural & 18 & 75 \\
\hline & Urban & 6 & 25 \\
\hline \multicolumn{2}{|c|}{ Previous episodes } & 4 & 17 \\
\hline \multicolumn{2}{|c|}{ Family History } & 0 & 0 \\
\hline \multicolumn{2}{|c|}{ Table 1. Summary of Demographic Data (n=24) } \\
\hline
\end{tabular}

\begin{tabular}{|c|c|c|c|}
\hline & Clinical Findings & Number & \% of Total \\
\hline \multirow{4}{*}{ Site } & Eye Brow & 1 & Multiple \\
& Scalp & 22 & parameters \\
& Beard & 3 & included \\
& Other & 1 & 4 \\
Pattern & Universalis & 1 & 4 \\
& Totalis & 1 & 79 \\
& Focal (patch) & 19 & 13 \\
\hline \multirow{2}{*}{ No. of } & Ophiasis & 3 & 75 \\
Patches & $<3$ & 18 & 4 \\
& $3-6$ & 1 & 21 \\
\hline Table 2. Shows Baseline Clinical Findings. Four Patients Had a \\
History of One Episode Each in The Past and None Had Any Family \\
\multicolumn{2}{|c|}{ History (n=24) } \\
\hline
\end{tabular}

\begin{tabular}{|c|c|c|c|c|c|c|c|c|c|c|c|c|c|c|c|}
\hline & \multicolumn{3}{|c|}{$\stackrel{3}{\stackrel{3}{0}}$} & \multicolumn{3}{|c|}{ 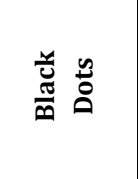 } & \multicolumn{3}{|c|}{ 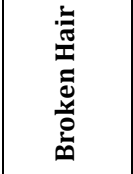 } & \multicolumn{3}{|c|}{ 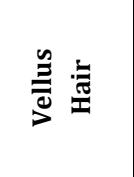 } & \multicolumn{3}{|c|}{ : } \\
\hline & : & $\begin{array}{l}\frac{\dot{n}}{3} \\
\dot{4}\end{array}$ & $\begin{array}{l}\frac{1}{3} \\
\frac{1}{3} \\
\infty\end{array}$ & 骂 & $\begin{array}{l}\frac{\dot{y}}{3} \\
\dot{4}\end{array}$ & $\begin{array}{l}\dot{0} \\
\frac{0}{3} \\
\infty\end{array}$ & : & $\begin{array}{l}\dot{y} \\
\frac{4}{3} \\
\dot{4}\end{array}$ & $\begin{array}{l}\dot{0} \\
\frac{4}{3} \\
\infty\end{array}$ & $\stackrel{\Xi}{\stackrel{\Xi}{\Xi}}$ & $\begin{array}{l}\frac{0}{3} \\
\dot{a}\end{array}$ & $\begin{array}{l}\dot{0} \\
\frac{2}{3} \\
\infty\end{array}$ & : & $\begin{array}{l}\dot{y} \\
\frac{x}{3} \\
+\end{array}$ & $\frac{\dot{n}}{3}$ \\
\hline $\begin{array}{c}\text { Present } \\
\text { in } \\
\text { (No. of } \\
\text { Patients) }\end{array}$ & 20 & 10 & 4 & 6 & 2 & 2 & 2 & 2 & 0 & 4 & 8 & 16 & 4 & 4 & 2 \\
\hline $\begin{array}{c}\text { Absent } \\
\text { in } \\
\text { (No. of } \\
\text { Patients) }\end{array}$ & 4 & 14 & 20 & 18 & 22 & 22 & 22 & 22 & 24 & 20 & 16 & 8 & 20 & 20 & 22 \\
\hline $\mathrm{p}$ value & - & $\begin{array}{l}\hat{O} \\
\text { Oุ } \\
0\end{array}$ & $\begin{array}{l}-\overrightarrow{0} \\
\dot{0} \\
0 \\
\dot{0} \\
v\end{array}$ & ' & $\stackrel{\stackrel{2}{+}}{\underset{0}{0}}$ & 志 & ' & 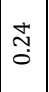 & $\begin{array}{l}\tilde{O} \\
0 \\
0\end{array}$ & , & $\ddot{m}$ & $\begin{array}{l}- \\
\\
0 \\
0\end{array}$ & & $\stackrel{0}{0}$ & $\stackrel{\bullet}{0}$ \\
\hline
\end{tabular}

Summary of dermoscopy findings at initial and follow up visits

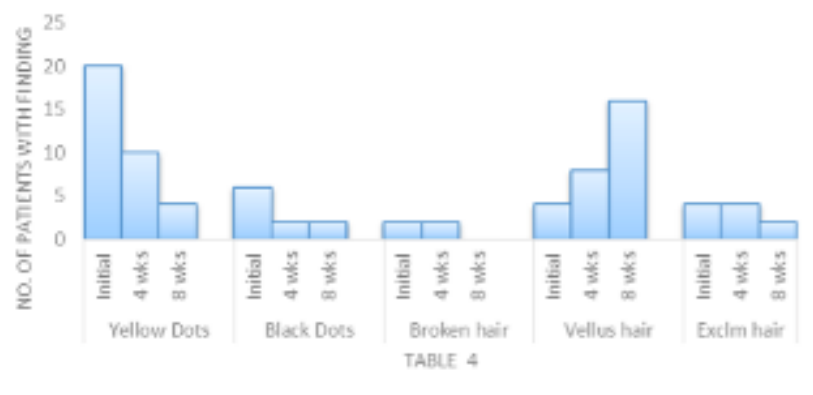

Table 4. Compound Bar Diagram Showing Change in Dermatoscopy Findings in Baseline, 1 st and $2^{\text {nd }}$ Follow Up 

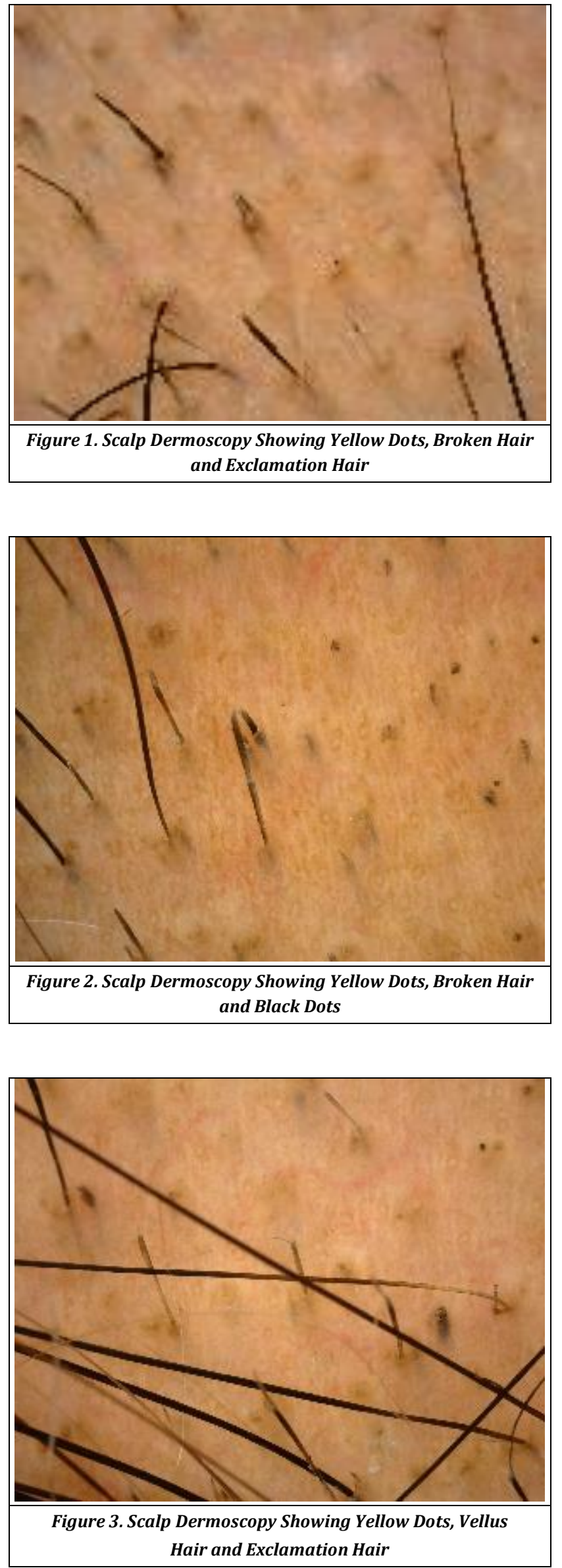

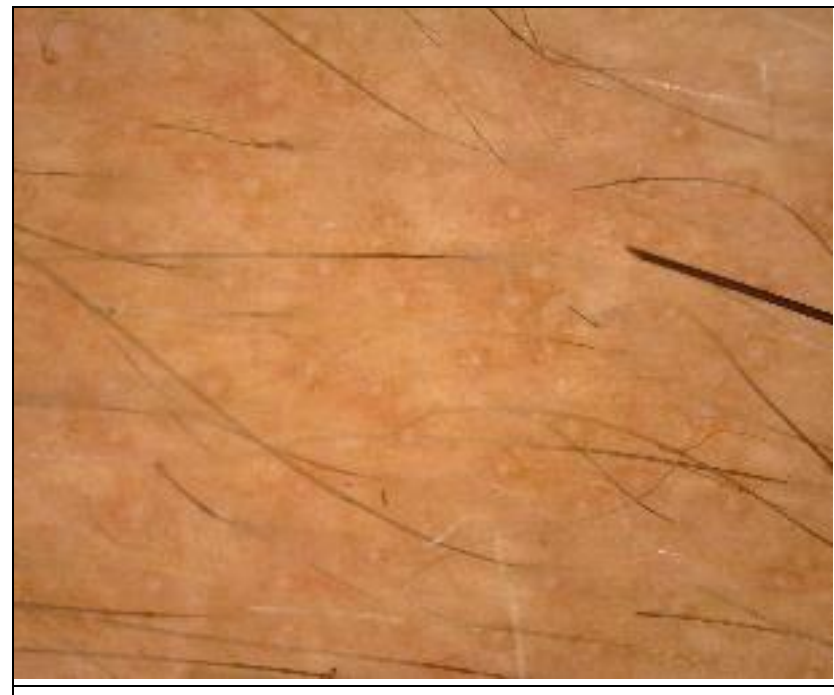

Figure 4. Scalp Dermoscopy Showing Yellow Dots, Vellus Hair

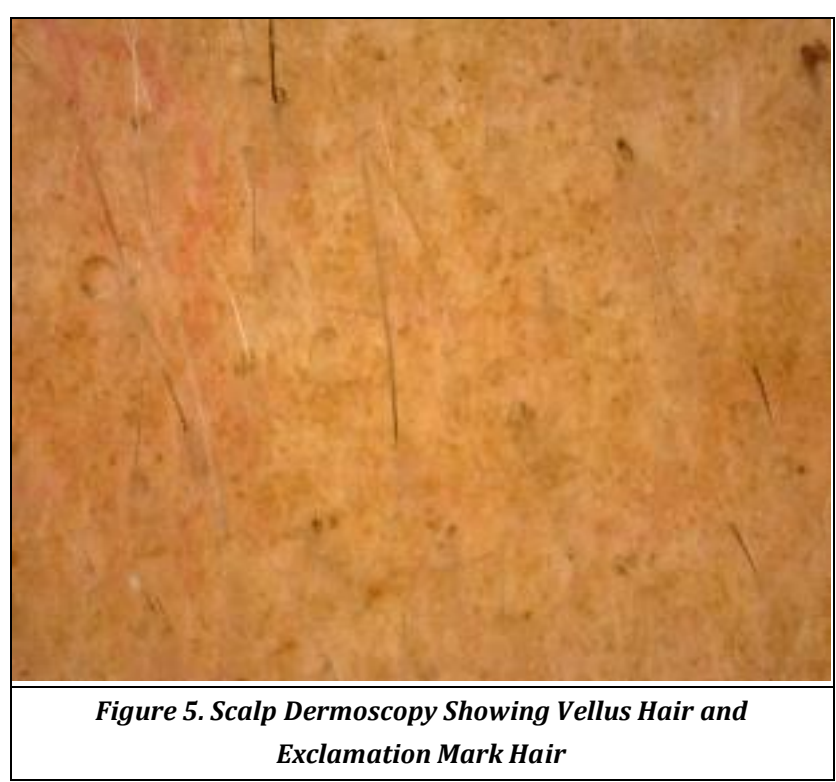

\section{Statistical Analysis}

The data collected was tabulated in Microsoft Excel worksheet and descriptive statistical analysis was carried out for presenting the dermoscopy parameters and sociodemographical parameters. The outcome variables (Clinical response and dermoscopy parameters) were assessed and quantified in each time point (at 4 weeks interval). For comparison of means, one-way ANOVA was used; Chi square test was used to determine statistical significance before and after therapy. All statistical analyses were carried out at 95\% confidence interval and the $\mathrm{p}$ value $<0.05$ was considered as significant.

\section{RESULTS}

A total of 25 patients were initially recruited for the study. Out of these, one patient was lost to follow up. The probable reason for such patient lost to follow up was the migratory nature of large number of labourers who attend our OPD. 
Table 1 shows the main demographic and clinical characteristics of enrolled patients. Table 2 represents the clinical findings at first visit. Table 3 summarises the dermoscopy findings at subsequent follow up. Table 4 displays the same findings as a bar diagram.

The patient with alopecia totalis was administered OMP, the patient with alopecia universalis received OMP with PUVA, while all others were treated with intralesional injections of triamcinolone acetonide $(5 \mathrm{mg} / \mathrm{ml})$ or topical therapy. They were then followed up; Table 3 summarizes the dermatoscopic findings.

Figure 1 depicts the same data as stacked columns (100\%).

\section{Yellow Dots}

YDs were present in 20 patients of 24 (83.3\%) at initial presentation (Figure 1,2,4). The number of patients with YDs decreased to $10(41.6 \%)$ at 4 weeks. It further decreased to 4 patients $(16.6 \%)$ at 8 weeks. The decrease was significant in both situations $(\mathrm{P}=0.007$ and $\mathrm{P}<0.0001$, respectively).

\section{Black Dots}

Black dots (BD) were present in 6 patients (25\%) initially (Figure 2). This decreased to 2 patients (8.3\%) each at 4 and 8 weeks. This decrease was not significant $(\mathrm{P}=0.24, \mathrm{P}=0.24)$.

\section{Broken Hairs}

Broken hairs (BH)s were present in 2 patients (8.3\%) initially and at 4 weeks (Figure 2, 3). This decreased to nil at the end of 8 weeks. The decrease at 4 weeks was not significant $(P=0.24)$ but significant after 8 weeks $(P=0.02)$.

\section{Coudability Hairs}

Coudability hairs $(\mathrm{CH})$ were not found in any patient.

\section{Vellus Hairs}

Vellus hairs (VH) were found in 4 patients (16.6\%) initially, 8 patients $(33 \%)$ at 4 weeks and 16 patients $(66.6 \%)$ at 8 weeks (Figure $2,3,5)$. This was not significant $(\mathrm{P}=0.31)$ at 4 weeks but significant at 8 weeks $(\mathrm{P}=0.001)$.

\section{Exclamation Mark Hairs}

Exclamation mark hairs (EH) were found in $16.6 \%$ of patients at initial visit (Figure 1,5). It remained same at 4 weeks and decreased at 8 weeks of the study $(\mathrm{P}=0.6625)$.

\section{DISCUSSION}

AA refers to round or oval patches of non-scarring hair loss and presents with circumscribed, totally bald, smooth patches. Short, easily extractable broken hairs, known as exclamation mark hairs, are often seen at the margins of the bald patches during active phases of the disease.

Yellow Dots (YDs) are marked by a distinctive array of yellow to yellow-pink, round or polycyclic dots that vary in size and are uniform in colour and constitute the most sensitive feature of AA.21,22 However, they are also observed in androgenetic alopecia and alopecia incognito. YDs in AA are keratinous and in AGA, represent sebaceous debris. ${ }^{23}$ In a study by Ganjoo S. for yellow dots to disappear completely in all the 70 patches, it took 16 weeks ${ }^{24}$. In our study, there was decreasing trend, but complete disappearance was seen in only $40 \%$ of patients during the follow up period.
Exclamation marks hairs (EH) are characterized by wider diameter in the distal shaft and thinner diameter in the proximal shaft. This pattern marks presence of the lymphocytic inflammatory infiltrate affecting the hair bulb and thus, producing thinner hair shaft, 25 In our study, 20\% patients had exclamation marks hairs initially.

Broken Hair (BH), considered to be dystrophic hairs produced by the least severely affected follicles in

AA and are clinical markers of the disease activity and severity. ${ }^{21}$ Similarly their subsequent decreasing trend has been seen in our study.

Black Dots (BD) (Formerly "cadaverized hairs") which represents pigmented hairs broken or destroyed at scalp level is characteristic of black-haired individuals. ${ }^{21}$ BDs are remnants of exclamation mark hairs or BHs. These are a sensitive marker not only for disease activity, but also for the severity of AA. BDs were found in $25 \%$ of our patients initially and decreased following treatment.

Vellus hair $(\mathrm{VH})$ is sensitive marker of hair re-growth. They appear either as coiled hair (circle hair) or as pigtail pattern as described by Rudnicka or lighter pigmented hairs tapering towards distal end. ${ }^{23}$ These are seen as new, thin and unpigmented hairs within the patch. ${ }^{26}$ The re-growth of VHs can be seen after treatment in dermoscopy even when the recovered hairs are hardly perceived by the naked eye. Short hypopigmented vellus hairs are characteristic of remitting disease. An increase in their number has been well established in our study $(\mathrm{P}=0.0013)$.

Inui $\mathrm{S}$ reported normal-looking, long hairs with tapering proximal ends in patients with AA. ${ }^{21}$ This finding (coudability hairs) was significantly associated with other trichoscopic features, such as black dots and exclamation mark hairs, and was also considered a trichoscopic marker of disease activity. ${ }^{27}$ In the beginning of our study, 3 patients had few coudability hairs, which decreased to 1 patient at the end of the study.

From the above, it may be inferred that YDs are sensitive indicator of remission of the condition, reduction being significant at as early as 4 weeks and also significant at 8 weeks. Thus, it was both a sensitive and specific indicator of response to treatment.

The reduction of number of patients with $\mathrm{VH}$ at 8 weeks was significant and so was the decrease of $\mathrm{BH}$.

Exclamation hair $(\mathrm{EH})$ is said to be specific to diagnosis of AA. However, the decrease of number of patients with EH was significant neither at 4 weeks nor at 8 weeks in the present study.

The reduction of $\mathrm{VH}$ and $\mathrm{BH}$ are early marker of response to treatment and is similar to findings of Inui $S$ and mean a subsidence of disease activity with treatment. Inui $S$ had found no statistically significant association of disease activity with yellow dots 21 . The present study does not seem to agree with their findings and suggests rather being a sensitive and specific indicator of remission. Possible explanation to this difference may be a relatively small sample.

\section{CONCLUSIONS}

Dermatoscopy is an important tool for depicting the disease progress, response to treatment and prognosis of alopecia areata (AA), serving as a source of quantifiable objective data. Decrease in the number of black dots and broken hair are good 
prognostic markers while yellow dots can persist for long even after stoppage of disease activity, but their presence is significant in diagnosing AA. Exclamation mark and coudability hair are pathognomonic to $\mathrm{AA}$ and their disappearance takes time. SVH and circle hair are most important in knowing the response to therapy and their serial counts can be quite helpful in finding out appropriate treatments for resistant cases much earlier than it becomes clinically obvious. Almost all of the previous studies have addressed static findings in AA. Our study differs in that here, each patient had been examined before and after the institution of treatment. Dermatoscopy should be performed especially in patients with poor prognostic factors so as to decide on changing or modifying the therapy. A dermatoscopy record should be maintained for each visit of the patient. This, apart from other benefits can be helpful in medicolegal purposes as well. Few of the findings cannot be explained probably due to shorter follow up; cases of alopecia totalis and universalis itself have poor prognosis. A larger sample size might be of help.

\section{REFERENCES}

[1] Wasserman D, Guzman-Sanchez DA, Scott K, et al. Alopecia areata. Int J Dermatol 2007;46(2):121-31.

[2] Alkhalifah A, Alsantali A, Wang E, et al. Alopecia areata update: part I. Clinical picture, histopathology and pathogenesis. J Am Acad Dermatol 2010;62(2):177-88.

[3] Ikeda T. A new classification of alopecia areata. Dermatologica 1965;131(6):421-45.

[4] Tosti A, Piraccini BM, Pazzaglia M, et al. Clobetasol propionate $0.05 \%$ under occlusion in the treatment of alopecia totalis/universalis. J Am Acad Dermatol 2003;49(1):96-8.

[5] Abell E, Munro DD. Intralesional treatment of alopecia areata with triamcinolone acetonide by jet injector. $\mathrm{Br} \mathrm{J}$ Dermatol 1973;88(1):55-9.

[6] Olsen EA, Carson SC, Turney EA. Systemic steroids with or without $2 \%$ topical minoxidil in the treatment of alopecia areata. Arch Dermatol 1992;128(11):1467-73.

[7] Sharma VK. Pulsed administration of corticosteroids in the treatment of alopecia areata. Int J Dermatol 1996;35(2):133-6.

[8] Friedli A, Labarthe MP, Engelhardt E, et al. Pulse methylprednisolone therapy for severe alopecia areata: an open prospective study of 45 patients. J Am Acad Dermatol 1998;39(4 Pt 1):597-602.

[9] Nakajima T, Inui S, Itami S. Pulse corticosteroid therapy for alopecia areata: study of 139 patients. Dermatology 2007;215(4):320-4.

[10] Sladden MJ, Hutchinson PE. Is oral pulsed prednisolone useful in alopecia areata? Critical appraisal of a randomized trial. J Am Acad Dermatol 2005;53 (6):1100-1.
[11] Happle R, Hausen BM, Wiesner-Menzel L. Diphencyprone in the treatment of alopecia areata. Acta Derm Venereol (Stockh) 1983;63(1):49-52.

[12] Rokhsar CK, Shupack JL, Vafai JJ, et al. Efficacy of topical sensitizers in the treatment of alopecia areata. J Am Acad Dermatol 1998;39(5 Pt 1):751-61.

[13] Claudy AL, Gagnaire D. PUVA treatment of alopecia areata. Arch Dermatol 1983;119(12):975-8.

[14] Lassus A, Eskelinen A, Johansson E. Treatment of alopecia areata with three different PUVA modalities. Photodermatol 1984;1(3):141-4.

[15] Mitchell AJ, Douglass MC. Topical photochemotherapy for alopecia areata. J Am Acad Dermatol 1985;12(4):644-9.

[16] Taylor CR, Hawk JL. PUVA treatment of alopecia areata partialis, totalis and universalis: audit of 10 years' experience at St John's Institute of Dermatology. Br J Dermatol 1995;133(6):914-8.

[17] Price VH. Double-blind, placebo-controlled evaluation of topical minoxidil inextensive alopecia areata. J Am Acad Dermatol 1987;16(3 Pt 2):730-6.

[18] Ranchoff RE, Bergfeld WF, Steck WD, et al. Extensive alopecia areata. Results of treatment with 3\% topical minoxidil. Cleve Clin J Med 1989;56(2):149-54.

[19] Fiedler-Weiss VC. Topical minoxidil solution (1\% and $5 \%$ ) in the treatment of alopecia areata. J Am Acad Dermatol 1987;16(3 Pt 2):745-8.

[20] Fiedler-Weiss VC, Buys CM. Evaluation of anthralin in the treatment of alopecia areata. Arch Dermatol 1987;123(11):1491-3.

[21] Inui $S$, Nakajima $T$, Nakagawa $K$, et al. Clinical significance of dermoscopy in alopecia areata: analysis of 300 cases. Int J Dermatol 2008;47(7):688-93.

[22] Ross EK, Vincenzi C, Tosti A. Videodermoscopy in the evaluation of hair and scalp disorders. J Am Acad Dermatol 2006;55(5):799-806.

[23] Jain N, Doshi B, Khopkar U. Trichoscopy in alopecias: diagnosis simplified. Int J Trichology 2013;5(4):170-8.

[24] Ganjoo S, Thappa DM. Dermoscopic evaluation of therapeutic response to an intralesional corticosteroid in the treatment of alopecia areata. Indian J Dermatol Venereol Leprol 2013;79(3):408-17.

[25] De Moura LH, Duque-Estrada B, Abraham LS, et al. Dermoscopy findings of alopecia areata in an AfricanAmerican patient. J Dermatol Case Rep 2008;2(4):52-4.

[26] Mane M, Nath AK, Thappa DM. Utility of dermoscopy in alopecia areata. Indian J Dermatol 2011;56(4):407-11.

[27] Safavi KH, Muller SA, Suman VJ, et al. Incidence of alopecia areata in Olmsted County, Minnesota, 1975 through 1989. Mayo Clin Proc 1995;70(7):628-33. 